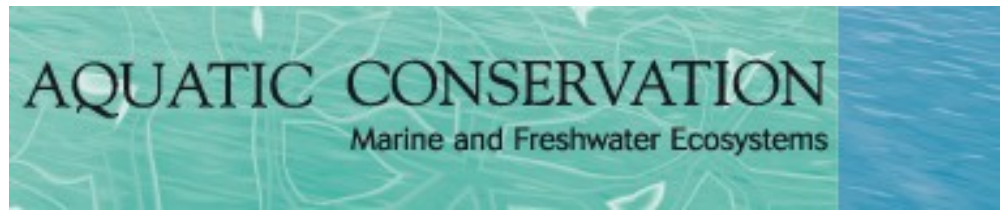

\title{
The diet of harbour and grey seals around Britain: examining the role of prey as a potential cause of harbour seal declines
}

\begin{tabular}{|r|l|}
\hline Journal: & Aquatic Conservation: Marine and Freshwater Ecosystems \\
\hline Manuscript ID & AQC-18-0288.R1 \\
\hline Wiley - Manuscript type: & Supplement Article \\
\hline Author: & n/a \\
\hline Complete List of Authors: & $\begin{array}{l}\text { Wilson, Lindsay; Sea Mammal Research Unit, SMRU } \\
\text { Hammond, Philip; Sea Mammal Research Unit, Scottish Oceans Institute, } \\
\text { University of St Andrews }\end{array}$ \\
\hline $\begin{array}{r}\text { Broad habitat type } \\
\text { (mandatory) select 1-2: }\end{array}$ & $\begin{array}{l}\text { coastal < Broad habitat type, ocean < Broad habitat type, sea loch }< \\
\text { Broad habitat type }\end{array}$ \\
\hline $\begin{array}{r}\text { General theme or application } \\
\text { (mandatory) select 1-2: }\end{array}$ & $\begin{array}{l}\text { feeding }<\text { General theme or application, behaviour < General theme or } \\
\text { application, predation < General theme or application }\end{array}$ \\
\hline $\begin{array}{r}\text { Broad taxonomic group or } \\
\text { category (mandatory, if } \\
\text { relevant to paper) select 1-2: }\end{array}$ & mammals < Broad taxonomic group or category \\
\hline $\begin{array}{r}\text { Impact category (mandatory, } \\
\text { if relevant to paper) select 1- } \\
2:\end{array}$ & \\
\hline & \\
\hline
\end{tabular}

\section{SCHOLARONE" Manuscripts}


The diet of harbour and grey seals around Britain: examining the role of prey as a

Lindsay J Wilson \& Philip S Hammond

Sea Mammal Research Unit, University of St Andrews

\section{potential cause of harbour seal declines}

(1)

\section{Abstract}

8 1. Harbour seal populations have declined over the last 20 years in some regions around 9 Britain. Causes are unknown but could include a reduction in prey availability which may 10 potentially be influenced by competition with grey seals. The diets of these two marine 11 predators overlap considerably, indicating that there could potentially be competition for 12 prey.

13 2. In this study, the diets of harbour and grey seals in 2010/12 are compared regionally and 14

\section{Key words} harbour seals have declined in regions where they appear to be reliant on sandeel and where sandeel stocks have declined, but not in regions where sandeel have never been an important component of the diet. A possible contributing reason for the harbour seal declines may therefore be a reduction in the availability of sandeel in these regions.

5. Sandeel continue to be an important (although reduced) prey in the diet of grey seals in regions where harbour seals have declined. If sandeel are a limiting resource, it is possible, therefore, that grey seals may reduce prey availability to harbour seals and contribute to their decline through competition.

coastal, ocean, sea loch, feeding, behaviour, predation, mammals 


\section{Introduction}

37

Grey seals (Halichoerus grypus) are sympatric with harbour seals (Phoca vitulina) over much of their North Atlantic range but these species show some spatial partitioning in their distribution on land and at sea (e.g. Jones, McConnell, Sparling, \& Matthiopoulos, 2013). Differences in the timing of annual breeding and moulting result in grey seals spending more time on land and harbour seals spending more time at sea during autumn and winter throughout their range (Boyd \& Croxall, 1996; Lowry, Frost, Hoep, \& Delong, 2001; Reder, Lydersen, Arnold, \& Kovacs, 2003; Simpkins, Withrow, Cesarone, \& Boveng, 2003; Thompson, Mackay, Tollit, Enderby, \& Hammond, 1998). The reverse is true in spring and summer when harbour seals spend more time on land (Thompson et al., 1998; Thompson, Miller, Cooper, \& Hammond, 1994) and grey seals more time at sea (Russell et al., 2015). These differences in phenology may be one way in which these sympatric high level predators partition their niches on an annual basis.

The abundance of grey seals around Britain has been increasing since the 1960s and the total population was estimated at 141,000 (95\% Cl 117,500 - 168,500) in 2016 (SCOS, 2017). Regionally, numbers have been more or less stable west of Scotland since the 1990s and in Orkney since the 2000s, albeit with some inter-annual variation; however, numbers continue to increase in the North Sea (SCOS, 2017).

In contrast, harbour seals around Britain are less numerous (total estimate 43,500; approx. $95 \% \mathrm{Cl} 35,600-58,000$ in 2016) and have declined in some regions (Shetland, Orkney and eastern Scotland) since around 2000 whilst remaining stable or having increased (Scottish west coast and Western Isles and eastern England) in others (Lonergan et al., 2007; SCOS, 2017). The causes of the declines are unknown (Sea Mammal Research Unit, 2012, 2014) but one possible contributing reason is competition with grey seals.

Aggressive interactions between individual grey and harbour seals have been observed at mixed species haul-out sites in some areas. These direct inter-specific interactions may be a form of interference competition with space on haul-out sites as a limiting resource. Aggressive intra-specific interactions have been shown to be related to pinniped density at haul-out sites. For example, Fernández-Juricic and Cassini (2007) found an increase in the rate of agonistic interactions with density in female South American sea lions, and Krieber and Barrette (1984) found a positive relationship between the proportion of aggressive interactions leading to animals leaving a site and the density of seals at the site.

Grey seals have also been observed predating on harbour seals and injuries on harbour seal carcasses consistent with grey seal predation are well-documented (Brownlow, Onoufriou, Bishop, Davison, \& Thompson, 2016; ICES, 2017; van Neer, Jensen, \& Siebert, 2015). However, it is not possible with current information to assess the extent of such predation nor, therefore, the population consequences of this predator-prey interaction (ICES, 2017). 
Harbour and grey seals may also compete for food. Diet studies around Britain show that the ranges of prey species consumed by harbour and grey seals overlap considerably. In particular, sandeel and large gadids have been important prey groups in the diet of grey seals for the last three decades (Hammond \& Wilson, 2016) and these prey also feature strongly in the diet of harbour seals around Britain (e.g. Brown, Pierce, Hislop, \& Santos, 2001; Hall, Watkins, \& Hammond, 1998; Pierce \& Santos, 2003; Sharples, Arrizabalaga, \& Hammond, 2009; Tollit \& Thompson, 1996; Wilson \& Hammond, 2016).

This overlap in diet could lead to exploitation competition if prey are a limiting resource, through which one or both species may be impacted indirectly by prey depletion. Comparison of harbour and grey seal diets can provide some information on the extent of the potential for these species to compete for prey. However, diet is the result of interactions among prey distribution, abundance and availability, and seal foraging distribution and behaviour, so comparison of diets can only ever provide part of the picture. In addition, even detailed observations of a system can only show the "ghost of competition past" (Connell, 1980), if such competition exists, and cannot directly address whether or not competition for prey is occurring. To demonstrate competition typically requires manipulative experiments (Connell, 1961; Paine, 1984; Paine, Castillo, \& Cancino, 1985) or a major natural change such as an extreme El Niño event (e.g. Paine \& Trimble, 2004).

Even in the absence of competition with grey seals for food, reduced prey availability could be a contributory cause of the decline in harbour seals in some regions of Scotland, especially if this had an impact at a critical life history stage. Fish assemblages have changed markedly in the North Sea in recent decades because of over-exploitation of some fish stocks and climate change (Christensen \& Richardson, 2008; Heath, 2005; Perry, Low, Ellis, \& Reynolds, 2005). In south-east Scotland, Frederiksen, Wanless, Harris, Rothery, and Wilson (2004) found temperature to influence plankton abundance and a positive correlation between plankton and sandeel larval abundance resulting in reduced sandeel recruitment in warm winters, suggesting that sandeel populations are driven by bottom-up effects. If such changes have reduced the availability of key prey to harbour seals they could contribute to the observed declines in Shetland, Orkney and south-east Scotland.

Interactions between sympatric marine predators and their prey are of interest in the context of changes in the marine environment both cyclical (such as the North Atlantic Oscillation) and unidirectional (ocean warming) but they are also of interest in a conservation and management context. The harbour seal and the grey seal are both listed under Annex II of the EU Habitats Directive requiring Member States to propose Special Areas of Conservation (SACs) under Natura 2000 and to act if human activities are threatening favourable conservation status (EEC, 1992). It is thus important to investigate whether harbour seals are declining for natural reasons, such as reduced prey availability driven by changes in hydrography or competition with grey seals for food, or directly as a result of manageable human activities. 
112 In this paper, regional variation in population trends in harbour and grey seals around

113 Britain was used as a kind of natural experiment, within which patterns in the diet of these 114 two species were compared that they might provide indications of whether or not 115 competition for food may be occurring.

116 The focus is on new information on the diet of harbour seals and grey seals from 117 comprehensive sampling throughout Scotland and eastern England in 2010/12 (Hammond \& 118 Wilson, 2016; Wilson \& Hammond, 2016). Equivalent results are available for grey seals 119 from 1985 and 2002 (Hammond \& Grellier, 2006; Hammond, Hall, \& Prime, 1994a, 1994b; 120 Hammond \& Wilson, 2016; Harris, 2007). Earlier information on harbour seal diet is 121 available from previous studies that were more restricted in time and space and, in most 122 cases, analytical treatment (Brown et al., 2001; Hall et al., 1998; Pierce \& Santos, 2003; 123 Sharples et al., 2009; Tollit \& Thompson, 1996), which makes comparison with diet in 124 2010/12 more challenging.

125 These results on diet are considered in the context of information on changes over time in 126 the abundance of the main prey species, which have generally declined in the last few 127 decades (ICES, 2018a; 2018b; 2018c; 2018d; 2018e). This approach was used to evaluate 128 the indirect evidence for impacts of declines in prey availability and consider whether 129 competition for food between harbour and grey seals might play a role. It is important to 130 stress that this evaluation can only provide circumstantial evidence supporting only weak 131 inferences and that any conclusions, therefore, remain largely speculative. In particular, it is 132 not known whether one or more prey species act as a limiting resource, a necessary 133 requirement for competition. It is therefore not possible to define which patterns would or 134 would not be expected if competition were or were not occurring because of lack of key 135 information. Nevertheless, the aim is that by an examination of the various sources of 136 information some insight can be gained into the role that predation and competition may 137 play in the decline of harbour seals in some regions around Britain.

\section{Methods}

\section{$140 \quad 2.1$ Sample collection}

141 Scats were collected in 2010/2012 within two hours of low water. All scats were placed into 142 separate plastic bags and stored at $-20^{\circ} \mathrm{C}$ and were expected to be no more than two weeks 143 old (since the previous spring tide). Supplementary Material Figure 1 shows locations where 144 harbour and grey seal scats were collected.

145 Seasonal stratification of sample collection and diet analysis was different between species 146 because of differences in the life cycles of the two species and to facilitate comparison of 147 grey seal results with earlier studies. For harbour seals, winter, spring, summer, and autumn 148 were defined as December-February, March-May, June-August, and September-November, 149 after Sharples et al. (2009). For grey seals these seasons were calendar quarters: January150 March, etc., to facilitate comparison with fisheries data, after Hammond and Grellier (2006). 
151 For this comparison of diets, data from the studies of Hammond and Wilson (2016) and 152 Wilson and Hammond (2016) were grouped for analysis into two seasons: spring/summer 153 (harbour seals: March-August; grey seals: April-September) and autumn/winter (harbour 154 seals: September-February; grey seals: October-March).

155 There were also differences in regional stratification between the studies of harbour and 156 grey seal diet. For harbour seals, regions matched the Scottish Government designated Seal 157 Management Regions (Baxter et al., 2011) and also included The Wash in south-east 158 England. For grey seals, the regions were broader: Inner Hebrides, Outer Hebrides, 159 Shetland, Orkney and the northern North Sea, central North Sea and southern North Sea, 160 allowing direct comparison with results from previous studies in 1985 and 2002 (Hammond 161 \& Grellier, 2006; Harris, 2007)

162 For regional comparison of diets, the data from Hammond and Wilson (2016) and Wilson 163 and Hammond (2016) were grouped into the following regions: southern North Sea, south 164 east Scotland (Firth of Forth, Isle of May, Rivers Tay, Eden and Ythan), Moray Firth, Orkney, 165 Shetland, Inner Hebrides and Outer Hebrides.

166 Before approaching a haul-out site, the number of harbour seals was counted and any grey 167 seals were identified and counted. Haul-out sites were designated as a single species site if 168 the area contained $\geq 80 \%$ of one species (based on a low misclassification rate of $3 \%$ in 169 molecular analyses to identify the species, Matejusová et al., 2013; Wilson, 2014) or if the seals were spatially segregated at the haul-out site.

\subsection{Sample processing}

Approximately 33 individual scats were defrosted, placed in nested mesh bags (inner 350 $\mu \mathrm{m}$, outer $240 \mu \mathrm{m}$ ) and soaked in $40 \mathrm{~L}$ warm water with $25 \mathrm{~g}$ Dreft detergent (P\&G, UK) for 2-24 h. Scats were subsequently machine washed (Orr et al., 2004), in a 73 L capacity machine following the protocol developed by S. Brasseur (pers. comm.); a $2 \mathrm{~h} 40^{\circ} \mathrm{C}$ pre-wash with $50 \mathrm{~g}$ detergent and $0.5 \mathrm{~h}$ wool wash at $40^{\circ} \mathrm{C}$ with $50 \mathrm{~g}$ detergent, the spin cycle was deactivated for all wash cycles. If pebbles had been picked up as part of an individual scat, otoliths and beaks were extracted using running water through a nest of sieves (mesh sizes $1801 \mathrm{~mm}, 600 \mu \mathrm{m}, 335 \mu \mathrm{m}$ and $250 \mu \mathrm{m}$ ) to avoid damage to prey hard remains. The presence of other possible prey remains (e.g. feathers and crustacean carapaces) was noted.

Sagittal otoliths were stored dry and identified to the lowest possible taxonomic group based on morphological criteria using a reference collection and identification guides (Härkönen, 1986; Leopold, van Damme, Philipart, \& Winter, 2001). Beaks were stored in $70 \%$ IMS and identified to species using a reference collection and identification guide 187 (Clarke, 1986). Where prey remains could not be identified to species, they were recorded 188 at a higher level (e.g. sandeel, unidentified gadid). 
190 Otolith lengths and widths were measured for all fish species where possible and 191 cephalopod lower rostral (squid species) or lower hood lengths (octopus species) were measured, all to the nearest $0.01 \mathrm{~mm}$, using digital callipers (Mitutoyo) under binocular microscopes. Broken otoliths and beaks were counted and measured only if the widest/longest part of the otolith, or the lower beak, was unbroken. Fragments of otoliths or beaks which were not large enough to be measured were not counted or measured to avoid misidentification of species and double counting.

All counted otoliths and beaks were measured except where a large number of otoliths of a prey species were recovered from a scat. In such cases, 30 otoliths were randomly chosen with respect to size and measured if there were 30-120 otoliths of the same species in a scat, and $25 \%$ were randomly chosen and measured if there were greater than 120 otoliths of the same species.

217 Estimation of seal diet composition generally followed the methods used in previous assessments of seal diet by the Sea Mammal Research Unit. Measurements of the size of otoliths (corrected for partial digestion) and beaks recovered from scats were used to estimate the weight of prey ingested. These values were summed across all scats in the region for each species, corrected for complete digestion, and expressed as percentages of the diet by weight (Hall et al., 1998; Hammond \& Grellier, 2006; Hammond et al., 1994a, 1994b; Hammond \& Rothery, 1996; Harris, 2007; Prime \& Hammond, 1990; Prime \& Hammond, 1987; Sharples et al., 2009).

Measurements of partially digested otolith/beak size were converted to estimates of undigested otolith/beak size using experimentally derived grade-specific digestion coefficients estimated separately for each seal species (Grellier \& Hammond, 2006; Tollit et 229 al., 1997; Wilson et al., 2017). For each prey species (or higher taxon) the preferred 230 measurement (otolith length or width, or lower rostral or lower hood length) was 
231 determined based on the availability of experimental data, the precision of the estimated 232 digestion coefficients (Grellier \& Hammond, 2006; Tollit et al., 1997; Wilson et al., 2017), the 233 measurement available from recovered hard parts and the availability of regression 234 equations to estimate prey size. Where species-specific correction factors were not 235 available, group-specific values were used (e.g. gadids, flatfish) or values from prey species with otoliths of similar size and robustness (Härkönen, 1986) were applied.

For dragonet (Callionymus lyra) and Cottidae species, digestion coefficients were only available for grey seals (Grellier \& Hammond, 2006). Species-on-species comparison showed that harbour seal digestion coefficients were generally smaller than grey seal digestion coefficients (by $8.3 \%$, on average). Grey seal digestion coefficients for dragonet and shortspined sea scorpion (bullrout) were, therefore, multiplied by 0.917 to use for harbour seals. For herring, estimated fish size was sensitive to the choice of DC for both harbour and grey seals. Based on a comparison of available DCs for harbour seals, the species-specific DC generated by Tollit et al. (1997) provided the most realistic estimates of fish size and was, therefore, used in the analyses.

For some prey species there was no suitable substitution and general "round fish" digestion coefficients were used. The use of values from other species or the general "round fish" value only occurred for prey species that were minor components of the diet.

Estimates of fish/cephalopod weight were derived from the estimates of undigested otolith/beak size using allometric equations (Clarke, 1986, GJ Pierce and MB Santos pers. comm.; Härkönen, 1986; Leopold et al., 2001; Santos, Clarke, \& Pierce, 2001). Where no equations were available for prey species, equations for the closest matching species were used; these species were all minor prey. For grey seals, grade-specific digestion coefficients for herring led to an unacceptable proportion of estimated sizes (weights and lengths) that were larger than the known size range of the species. There was no obvious explanation for this anomaly. As an ad hoc solution to rectify this problem, the grade 1 digestion coefficient was applied to all otolith measurements regardless of their assigned grade; this generated sizes that were mostly within the known size range. This anomaly is discussed further in Hammond and Wilson (2016).

For scats in which a sub-sample of the otoliths identified for a species had been measured, the fish weight represented by each unmeasured otolith was assumed equal to the mean weight of all measured otoliths of that species in that scat. This was also assumed for broken otoliths without an appropriate measurement. If there were no measured otoliths of that species in that scat, the mean weight of that species over all scats was used.

270 For each region/season, the estimated weights of prey represented by all fish otoliths and 271 cephalopod beaks were summed across all scats within species. To account for species- 
specific differences in complete digestion, the weight estimated for each prey species was adjusted using experimentally derived recovery rates, derived as a proportion of otoliths/beaks fed that were recovered. (Grellier \& Hammond, 2006; Wilson et al., 2017). Where no experimental data were available, group-specific values (e.g. gadids, flatfish) or values for the closest matching species were used. Diet composition was estimated as the percentage that each species contributed to the total estimated weight consumed.

Prey species were assigned to prey groups to facilitate general comparisons (see Supplementary Material Table 1). Large gadids mainly included cod, haddock, ling, rockling, saithe and whiting. Flatfish mainly included dab, Dover sole, flounder, lemon sole, plaice and witch. Sandy benthic mainly included dragonet and goby. Scorpion fish mainly included bullrout and sea scorpion. Pelagic mainly included herring, mackerel and sprat.

95\% confidence limits around estimates of diet composition were obtained using the method described by Hammond and Rothery (1996) as described and presented in Hammond and Wilson (2016) and Wilson and Hammond (2016). Non-parametric bootstrap resampling was used to estimate sampling error, with scat as the sampling unit. Each data set was resampled 1,000 times. Measurement error was estimated using parametric resampling of the coefficients describing the relationships used to obtain estimates of diet composition from otolith/beak measurements. All coefficients were resampled at each bootstrap replicate. Variability in measurement error was associated with (i) estimating undigested otolith/beak size from partially digested measurements via species- or gradespecific digestion coefficients; (ii) estimating fish/cephalopod weight from estimated undigested otolith/beak size via species-specific allometric relationships and (iii) accounting for complete digestion of otoliths/beaks using estimated recovery rates. $95 \%$ confidence limits were estimated as the $2.5 \%$-ile and $97.5 \%$-ile of the bootstrapped distributions.

\subsection{Diet Diversity}

Diet diversity was estimated for each region within a season using estimates of prey species richness and the relative abundance of prey species (species evenness). Species Richness (S) was calculated as the total number of species identified in the sample and evenness was measured using Pielou's evenness index (PEI). PEI provides a measure of how different the abundances of the species in a community are from each other (Smith \& Wilson, 1996).

Rarefaction analysis was used to standardize for sampling effort (number of scats collected) and to adjust for differences in sampling intensity, allowing meaningful comparison of datasets (Gotelli \& Colwell, 2001; Gotelli \& Colwell, 2011; Simberloff, 1978). This incurs loss of information but this is necessary to allow valid comparison.

To generate species richness, the rarefied (reduced) number of scats was randomly resampled multiple times from the total number of scats and the number of species 
determined. The data were rarefied to the minimum number of scats across regions within a season. Note that this means that species richness can only be compared across regions within seasons not across seasons.

PIE was calculated as $\mathrm{J}=\frac{H^{\prime}}{\log (S)}$ where $H^{\prime}$ is the Shannon-Weiner diversity index and $S$ is the rarefied total number of species in a sample. The value of $J$ ranges from 0 to 1 , with larger values representing more even distributions in abundance among species.

\section{Results}

In total, 65,534 otoliths and beaks were recovered from 1,976 harbour seal scats and 68,465 otoliths and beaks were recovered from 2,205 grey seal scats collected in 2010/12. Table 1 shows the breakdown of the number of scats collected in each region/season. Supplementary Material Table 1 shows the number of otoliths/beaks of each prey species recovered from scats, by region. Estimates of the percentage of the diet for each seal species, by season, in each prey group and in each of the main prey species are given in Table 2 and Supplementary Material Table 2, respectively.

Estimated 95\% confidence intervals are given in Supplementary Material Tables 3 and 4 . The intervals are wide for most prey species in most seasons and regions. Precision is greater for prey groups than for prey species, and for major components of the diet, especially sandeel. Because precision is generally poor, caution should be exercised when drawing quantitative inferences about differences in the diet. In this comparison of diet, therefore differences are primarily described qualitatively.

\subsection{Dietary comparison east of Britain / North Sea}

Grey seal diet was dominated by sandeel in all regions of the North Sea (southern North Sea, south-east Scotland and the Moray Firth). Although sandeel were also dominant in the diet of harbour seals in the Moray Firth ( $>75 \%$ in both seasons), in the southerly regions their diet was more varied in composition and included sandeel, flatfish, sandy benthic and large gadid prey.

In the southern North Sea, harbour seals ate mostly sandy benthic prey, flatfish and sandeel in spring/summer (SS) and flatfish, large gadids and sandy benthic prey in autumn/winter (AW) (Table 2 and Supplementary Material Table 2 for the main prey species). Grey seal diet was dominated in both seasons by sandeel but also included large gadids and flatfish in SS, with a change to scorpion fish, sandy benthic, large gadid and flatfish prey in AW (Table 2 and Supplementary Material Table 2). The number of prey species consumed by both species was similar in the region; however, harbour seal diet was spread much more evenly across the prey species (Table 3 ).

In south-east Scotland, the diet of harbour seals was dominated by sandeel and flatfish in SS with lesser contributions of large gadids. In AW, flatfish dominated with large gadids, 
pelagic and cephalopod prey making up the remainder of the diet (Table 2 and

Supplementary Material Table 2). Grey seal diet was dominated by sandeel in SS and to a lesser extent in AW; other important prey in AW included large gadids and flatfish (Table 2 and Supplementary Material Table 2). Species richness in the diet was similar for both seal species in SS but grey seals consumed fewer prey species in AW and grey seal diet was more uneven in both seasons than harbour seal diet (Table 3).

In the Moray Firth, the diet of both species was dominated by sandeel throughout the year (minimum contribution 67\% harbour seals in SS, Table 2 and Supplementary Material Table 2). Flatfish were also important in the diet of harbour seals in SS (Table 2 and Supplementary Material Table 2). The dominance of sandeel in the diet is reflected in the very low species diversity in the diet for both species (Table 3).

\subsection{Dietary comparison in the Northern Isles}

364 The diet of harbour and grey seals in Orkney and Shetland comprised mostly sandeel, large gadids and pelagic prey across both seasons and, for grey seals, scorpion fish in Shetland in SS. The largest difference in the diet of the two species was in Orkney AW and all year in Shetland, where harbour seals ate a higher estimated percentage of pelagic fish than grey seals. In Orkney in SS, harbour seals also ate a higher estimated percentage of sandeel than grey seals.

In Orkney in SS, sandeel and pelagic prey dominated harbour seal diet while grey seal diet comprised large gadids, sandeel and pelagic prey (Table 2 and Supplementary Material Table 2). In AW, harbour seal diet was dominated by pelagic and large gadid prey, although sandeel were also important, and grey seal diet comprised mostly large gadids, sandeel and pelagic fish (Table 2 and Supplementary Material Table 2). Grey seal diet composition was much more evenly spread across prey species with no contributions to the diet greater than $20 \%$ in SS or $30 \%$ in AW. Overall grey seal diet was more diverse, as reflected in the greater species richness and evenness, than harbour seal diet (Table 3 ).

The diet of harbour seals in Shetland in SS and AW was dominated by pelagic fish, sandeel and large gadids (Table 2 and Supplementary Material Table 2). Grey seal diet was dominated by large gadids and scorpion fish in SS and large gadids and sandeel in AW (Table 2 and Supplementary Material Table 2). Species richness was similar for harbour and grey seals in SS, but much greater for grey seals in AW (Table 3); grey seal diet was more even than harbour seal diet in both seasons (Table 3).

\subsection{Dietary comparison west of Scotland}

385 Large gadid prey were important in the diet of both harbour and grey seals west of Scotland.

386 Pelagic fish were also important in harbour seal diet, and sandeel and sandy benthic prey in 387 grey seal diet (Table 2 and Supplementary Material Table 2). 
388 In the Outer Hebrides, diet could only be estimated in SS for harbour seals and AW for grey 389 seals, so no comparison within seasons is possible. Harbour seal diet in SS was split across 390 five main prey groups; Trisopterus species, pelagic fish, large gadids, scorpion fish and 391 sandeel. Grey seal diet in AW was dominated by sandeel and large gadids with the 392 remaining prey groups individually contributing less than $10 \%$ to the diet.

393 In SS in the Inner Hebrides, harbour seal diet mostly comprised large gadids, and some 394 pelagic fish and Trisopterus species. Grey seal diet was dominated by large gadids and 395 sandy benthic prey with additional contributions from Trisopterus species. In AW, the diet 396 of harbour seals was predominantly large gadids and pelagic fish while the diet of grey seals 397 was mostly large gadids and sandeel. Dietary species richness was greater for harbour seals 398 than grey seals in SS but similar between species in AW. The diet of both species was 399 diverse (high evenness), reflected in the diet composition estimates in which no one prey 400 species dominated the diet in either seal species or season (Table 3).

4013.4 Overall comparison of harbour and grey seal diets

402 A summary comparison of the diet of harbour and grey seals in 2010/12 in relation to 403 regional population trends is given in Table 4. In terms of diet composition, in the southern 404 North Sea, sandeel strongly dominates grey seal diet but flatfish, gadid and sandy benthic 405 prey are much more important for harbour seals. In south-east Scotland, grey seal diet is 406 also dominated by sandeel, which is also an important prey for harbour seals together with 407 flatfish and gadids. In the Moray Firth, the diet of both species is strongly dominated by 408 sandeel. In Orkney and Shetland, sandeel and gadids are the mainstay of harbour and grey 409 seal diets, with pelagic prey also important for harbour seals. Gadids are the main prey of 410 both seal species in the Inner Hebrides.

411 Prey evenness, a measure of how diverse the diet is and how evenly it is spread among 412 multiple prey species, for harbour seals is greater than or equal to that of grey seals in all 413 regions and seasons except in spring/summer in Orkney and Shetland, where harbour seals 414 have declined. However, in south-east Scotland, where harbour seals have also declined, the 415 evenness of harbour seal diet is greater than that of grey seals.

416 Overall, the qualitative seasonal comparison summarized in Table 4, supported by the 417 detailed results given in Wilson and Hammond (2016) and Hammond and Wilson (2016), 418 shows that differences in diet between harbour and grey seals did not vary greatly between 419 Spring/Summer and Autumn/Winter. There is thus no evidence that diet differences are 420 related to seasonal differences in the life cycles of the two species.

\section{Discussion}

This study compared new and previous information on harbour and grey seal diets in the context of regional variation in recent trends in population size with the primary aim of 
investigating whether or not any patterns that emerged could be consistent with reduction in prey availability or competition for prey. Table 4 summarizes a comparison of current (2010/12) diet composition and evenness together with an indication of regional population trends.

Overall, the 2010/12 results confirm the regional and seasonal variation in diet observed in previous studies and that some prey types are more important in the diet than others. Sandeel and large gadids have consistently been the most important prey groups in the diet of grey seals for the last three decades (Hammond \& Grellier, 2006; Hammond et al., 1994a, 1994b; Hammond \& Wilson, 2016; Prime \& Hammond, 1990) and are also important in the diet of harbour seals both currently (Wilson \& Hammond, 2016) and previously (Brown et al., 2001; Hall et al., 1998; Pierce \& Santos, 2003; Sharples et al., 2009; Tollit \& Thompson, 1996). Below, regional, seasonal and temporal variation in the contribution of these two prey types to the diets of harbour and grey seals are considered in the context of available information on fish stock sizes.

\subsection{Importance of sandeel in the diet of harbour and grey seals}

Sandeel is an important prey of many marine predators including large gadids, seabirds and mammals (Harwood \& Croxall, 1988). Estimated sandeel stock biomass in the North Sea declined from the 1980s in the southern/central North Sea and from the 1990s in the central/northern North Sea through the 2000s, but has been higher, although highly variable since 2010 (ICES, 2018a; 2018b). Seabird breeding failure in the north-west North Sea has been linked to a reduction in the availability of sandeel (Wanless, Harris, Redman, \& Speakman, 2005) and to reduced sandeel recruitment in warm winters (Frederiksen et al., 2004). There are no sandeel stock assessments west or north of Scotland but catches in the Orkney/Shetland area declined steeply in the 1980 s and have been zero since the early 2000s (ICES 2018c).

Overall, the results for 2010/12 show that sandeel remains a very important prey for harbour and grey seals (Table 4). There is considerable variability in the results but there is a tendency for sandeel to be more dominant in the diet of both species in the North Sea and Northern Isles than west of Scotland. Sandeels tend to be more important in the diet of grey seals in autumn/winter in the Northern and Western Isles, but in spring/summer in the southern/central North Sea. In some regions there is a weak tendency for sandeel to be more dominant in the diet of harbour seals in spring/summer than in autumn/winter. Overall, however, there is no strong evidence for a consistent seasonal difference in the importance of sandeel in the diet of either seal species.

Comparing the 2010/12 results with those from previous studies, estimates of the proportion of sandeel in the diet have increased for both harbour and grey seals in the southern North Sea, where both seal species are increasing, and they have also increased for grey seals in the central North Sea, where they are increasing (Hall et al., 1998; Hammond \& Grellier, 2006; Hammond \& Wilson, 2016; Wilson \& Hammond, 2016). Sandeel 
has consistently remained the dominant prey in the diet of harbour seals in the Moray Firth (Pierce, Miller, Thompson, \& Hislop, 1991; Wilson \& Hammond, 2016), where seal numbers have been variable. In south-east Scotland, where harbour seals numbers have declined sharply, the importance of sandeel in their diet remains high but appears to have decreased, while that of flatfish has increased (Sharples et al., 2009; Wilson \& Hammond, 2016).

In Orkney and Shetland, where grey seal populations are stable, the proportion of sandeel in their diet has declined (Hammond \& Grellier, 2006; Hammond \& Wilson, 2016; Harris, 2007). Inferring changes in the importance of sandeel in the diet of harbour seals, which have declined in these regions, requires accounting for the fact that these studies did not incorporate correction for complete digestion of otoliths (Brown \& Pierce, 1998; Brown et al., 2001; Pierce, Boyle, \& Thompson, 1990). It is straightforward to calculate how the percentage of sandeel in the diet changes when complete digestion is taken into account, depending on the overall species composition in the diet. For diets covering the range of species composition observed in these earlier studies, the percentage of sandeel in the diet increases by a few percent when it is already high to by around $50 \%$ when the diet is dominated by gadids. From these approximate corrections it is clear that estimates of the amount of sandeel in harbour seal diet in Orkney and Shetland were higher in earlier years (late 1980 s to late 1990 s) than in 2010/12. The conclusion can therefore be drawn that while sandeel remain an important prey for harbour seals in these areas, their contribution has declined.

Although there are gaps in the available information, a general pattern emerges from these results. In regions where harbour seals have declined (northern and eastern Scotland) sandeel stocks have also declined and, although estimates of their contribution to the diet have declined, they remain an important prey. In contrast, in regions where harbour seals have not declined (west coast of Scotland, southern North Sea), sandeel remain relatively unimportant in the diet, which is more diverse (higher evenness) than in regions where they have declined. For grey seals, the dominance of sandeel in the diet has been maintained year-round in the southern/central North Sea, where populations are still increasing. In other regions, where populations are stable, estimates of the importance of sandeel have declined (Northern Isles) or remained low (West of Scotland).

Harbour seals have thus declined in regions where they appear to be reliant on sandeel and where sandeel stocks have declined, but not in regions where sandeel have never been an important component of the diet. A possible contributing reason for the declines may therefore be because of a reduction in the availability of sandeel in these regions. Sandeel continue to be an important (although reduced) prey in the diet of grey seals in regions where harbour seals have declined. If sandeel are a limiting resource, it is possible, therefore, that grey seals may reduce prey availability to harbour seals, and contribute to their decline through competition.

\subsection{Importance of large gadids in the diet of harbour and grey seals}


Large gadid fish have been heavily exploited for human consumption world-wide and the seas around Britain are no exception. The main demersal fisheries around Scotland are for cod, haddock and whiting. In 2002, the west of Scotland cod and whiting stocks were considered to be outside safe biological limits, as was the haddock stock to the west and north of Scotland (Gordon, Magill, Sayer, \& Barrington, 2002). In the same year, these species were shown to be major components of grey seal diet west of Scotland, with the likelihood that grey seals may be inflicting significant predation mortality on cod stocks (Hammond \& Wilson, 2016; Harris, 2007).

Current ICES stock assessments show that over the period for which there is seal diet information (1985-2010/12), the estimated size of the haddock stock in the North Sea and west of Scotland fluctuated considerably with generally lower stock sizes in the 1990s than in the 1980s and 2000s (ICES, 2018d). In contrast, cod declined steadily in the greater North Sea until 2005, since when it has recovered somewhat (ICES, 2018e), and also declined sharply west of Scotland with no sign of recovery (ICES, 2018f) - but see below. Whiting has remained more or less stable in the North Sea (ICES, 2018e) but declined sharply between 1996 and 2006 west of Scotland with only recent signs of recovery (ICES, 2018h).

Cook and Trijoulet (2016) and Trijoulet, Holmes, and Cook (2017) incorporated grey seal predation in fish stock assessment models of west of Scotland cod, which indicate that the stock is not as depleted as shown in ICES assessments (e.g. ICES, 2018f). A revised assessment has found similar results generated by alternative assumptions about fish selectivity without incorporating seal predation (Cook, in press). A multispecies assessment model including grey seals, cod, haddock and whiting west of Scotland found little evidence that seal predation mortality affected fish stock dynamics (Fallon et al., In prep).

Results for 2010/12 show that these species of large gadid fish are important prey for both grey and harbour seals in the Northern Isles and west of Scotland. In these regions, large gadids comprise around one-third of the diet overall; this proportion is remarkably consistent considering the inherent variability in the estimates. There is no indication of any seasonal variation in the contribution of large gadids to the diet of either harbour or grey seals. In the central and southern North Sea, large gadids are more minor components of both harbour and grey seal diet, but are more important in autumn/winter than in spring/summer (Table 4).

Comparing the 2010/12 results with those from previous studies, since 1985 the estimated contribution of large gadids to the diet of grey seals has increased in the Northern Isles, where harbour seals are declining, but stayed approximately the same in the southern North Sea and west of Scotland, where harbour seals are not declining (Hammond \& Grellier, 2006; Hammond et al., 1994a, 1994b; Hammond \& Wilson, 2016; Harris, 2007). For harbour seals, the available information from the temporally, spatially, and in most cases, analytically restricted limited previous studies shows no evidence that the importance of large gadids in the diet has changed west of Scotland since 1993-94, in the Moray Firth since 1988-92, in Shetland since 1994-96, in the southern North Sea since 1990-92 and in south- 
east Scotland since 1998-2002 (Brown \& Pierce, 1998; Hall et al., 1998; Pierce \& Santos, 2003; Sharples et al., 2009; Tollit \& Thompson, 1996).

In summary, there is a negative correlation between the change in contribution of large gadids to the diet of grey seals and the population trend in harbour seals, but otherwise no signal emerges from the spatio-temporal patterns in the available information. Considering the changes in stock size of the main species of large gadids together with the patterns in the importance of these species in the diet of harbour and grey seals regionally and over time, there is no evidence that harbour seal declines in some regions may be caused by reduced large gadid prey availability or possible competition for prey with grey seals.

\subsection{Dietary and prey comparison in a wider context}

553 Generally speaking, the overall increase in the numbers of seals in British waters (SCOS, 554 2017) and the historically low stock levels of some of their main prey species (ICES, 2018d, 555 2018e, 2018f, 2018g, 2018h) provide potential for intra-specific and inter-specific 556 competition between harbour and grey seals for food.

There has been a general increase in non-commercial prey species in the diet of grey seals over the last 30 years (Hammond \& Grellier, 2006; Hammond et al., 1994a, 1994b; Hammond \& Wilson, 2016; Harris, 2007) and these prey, including sandy benthic species, primarily dragonet, and scorpion fish, are also a major part of current harbour seal diet in some regions (Wilson \& Hammond, 2016). Thus, both grey and harbour seals may have responded to the changing fish assemblage around Britain by consuming more of those species that may have become more available relative to other species that have declined.

Measures of diet provide information on the types and relative amounts of prey consumed but provide no information on the costs of acquiring that prey. Information on diet alone is insufficient to determine whether changes in the relative abundance and availability of prey may have led to changes in the ability of seals to meet their nutritional requirements, including any influence of competition. Sharples, Moss, Patterson, and Hammond (2012) found no evidence for a relationship between harbour seal regional population trend and foraging trip duration or distance. Similarly, Russell et al. (2015) found that the relationship between time spent resting (at sea and on land) and population trend was the opposite of that expected if harbour seals were spending more time at sea foraging in areas where populations were declining.

These studies focused on seal foraging and haul-out behaviour. Smout, Rindorf, Hammond, Harwood, and Matthiopoulos (2014) fitted multispecies functional response models to data on the diet of grey seals and prey availability based on measures of the overlap between the distribution of foraging seals and their prey. Applying such modelling approaches to harbour seals around Britain, at appropriate spatial and temporal scales, could provide an important 579 additional dimension to investigation of whether reduction in prey availability could be a contributing cause of declines in harbour seals in some regions. Assessing whether grey 581 seals may influence the relationship between harbour seals and their prey will require 
extension of this model framework to include other predators, such as harbour porpoise, as well as multiple prey.

\section{vi. Acknowledgements}

Thanks are due to all landowners and site managers across all regions for allowing access to haul-out sites and for their overall support of this work. We are grateful to John Watkins (The Wash, south-east England), Kenny Meason (Shapinsay, Orkney), Annabel Drysdale (Forvie NNR) Scottish Natural Heritage, Rob Scott (Donna Nook) Lincolnshire Wildlife Trust and Ed Stubbings (Blakeney Point) National Trust for collecting scats on our behalf. Sample processing assistance was provided by Caya Sievers, Mel Froude, Mia Kent, Chris McKnight, Sian Tarrant, Donald Malone, and undergraduate diet team volunteers. John Watkins identified otoliths and Caya Sievers identified cephalopod beaks recovered from scats. Janneke Ransijn plotted the map of scat collection locations. Scottish Natural Heritage provided support to LW through a CASE award. Natural England provided support for scat collection in eastern England. We are grateful for the useful critical comments from the reviewers.

\section{vii. References}

Baxter, J. M., Boyd, I., Cox, M., Donald, A. E., Malcolm, S. J., Miles, H., . . Moffat, C. F. (2011). Scotland's Marine Atlas: Information for the national marine plan. Marine Scotland, Edinburgh.

Boyd, I. L., \& Croxall, J. P. (1996). Dive durations in pinnipeds and seabirds. Canadian Journal of Zoology, 74, 1696-1705.

Brown, E. G., \& Pierce, G. J. (1998). Monthly variation in the diet of harbour seals in inshore waters along the southeast Shetland (UK) coastline. Marine Ecology Progress Series, 167, 275-289.

Brown, E. G., Pierce, G. J., Hislop, J. R., \& Santos, M. B. (2001). Interannual variation in the summer diets of harbour seals Phoca vitulina at Mousa, Shetland (UK). Journal of the Marine Biological Association of the United Kingdom, 81, 325-337.

Brownlow, A., Onoufriou, J., Bishop, A., Davison, N., \& Thompson, D. (2016). Corkscrew Seals: Grey Seal (Halichoerus grypus) Infanticide and Cannibalism May Indicate the Cause of Spiral Lacerations in Seals. PLoS ONE, 11, e0156464.

Christensen, J. T., \& Richardson, K. (2008). Stable isotope evidence of long-term changes in the North Sea food web structure. Marine Ecology Progress Series, 368, 1-8.

Clarke, M. R. (1986). A handbook for the identification of Cephalopod beaks. Oxford: Clarendon Press

Connell, J. H. (1961). The influence of interspecific competition and other factors on the distribution of the barnacle Chthamalus stellatus. Ecology, 42, 710-723.

Connell, J. H. (1980). Diversity and the coevolution of competitors, or the ghost of competition past. Oikos, 131-138.

Cook, R.M. (in press). Stock collapse or stock recovery? Contrasting perceptions of a depleted cod stock. ICES Journal of Marine Science.

Cook, R. M., \& Trijoulet, V. (2016). The effects of grey seal predation and commercial fishing on the recovery of a depleted cod stock. Canadian Journal of Fisheries and Aquatic Sciences, 73, 1319-1329.

Council Directive 92/43/EEC of 21 May 1992 on the conservation of natural habitats and of wild fauna and flora, (1992). 
Fallon, N. G., Bartolino, V., Elvarsson, B. P., Hammond, P. S., Baudron, A. R., \& Fernandes, P. G. (In prep). Towards ecosystem-based fisheries management: modelling grey seal interactions with commercially important demersal fish species in the west of Scotland.

Fernández-Juricic, E., \& Cassini, M. H. (2007). Intra-sexual female agonistic behaviour of the South American sea lion (Otaria flavescens) in two colonies with different breeding substrates. Acta Ethologica, 10, 23-28.

Frederiksen, M., Wanless, S., Harris, M. P., Rothery, P., \& Wilson, L. J. (2004). The role of industrial fisheries and oceanographic change in the decline of North Sea black-legged kittiwakes. Journal of Applied Ecology, 41, 1129-1139.

Gordon, J. C. D., Magill, S., Sayer, S., \& Barrington, J. (2002). DTI Strategic Environmental Assessment Area 7.

Gotelli, N. J., \& Colwell, R. K. (2001). Quantifying biodiversity: procedures and pitfalls in the measurement and comparison of species richness. Ecology letters, 4, 379-391.

Gotelli, N. J., \& Colwell, R. K. (2011). Estimating species richness. In A. E. Magurran \& B. J. McGill (Eds.), Biological Diversity (pp. 39-54). Great Clarendon Street, Oxford: Oxord University Press.

Grellier, K., \& Hammond, P. S. (2006). Robust digestion and passage rate estimates for hard parts of grey seal (Halichoerus grypus) prey. Canadian Journal of Fisheries and Aquatic Sciences, 63, 1982-1998.

Hall, A. J., Watkins, J., \& Hammond, P. S. (1998). Seasonal variation in the diet of harbour seals in the south-western North Sea. Marine Ecology Progress Series, 170, 269-281.

Hammond, P., \& Grellier, K. (2006). Grey seal diet composition and prey consumption in the North Sea.Final report to Department for Environment Food and Rural Affairs on project MF0319.

Hammond, P., Hall, A., \& Prime, J. (1994a). The diet of grey seals around Orkney and other island and mainland sites in north-eastern Scotland. Journal of Applied Ecology, 31, 340-350.

Hammond, P., Hall, A., \& Prime, J. (1994b). The diet of grey seals in the Inner and Outer Hebrides. Journal of Applied Ecology, 31, 737-746.

Hammond, P., \& Rothery, P. (1996). Application of computer sampling in the estimation of seal diet. Journal of Applied Statistics, 23, 525-534.

Hammond, P., \& Wilson, L. (2016). Grey seal diet composition and prey consumption. Scottish Marine and Freshwater Science, 7, 20-47.

Härkönen, T. (1986). Guide to the otoliths of the bony fishes of the northeast Atlantic. Hellrup, Denmark: Danbiu ApS: Biological Consultants.

Harris, R. (2007). Assessing grey seal diet in western Scotland. Unpublished MPhil thesis. University of St Andrews.

Harwood, J., \& Croxall, J. P. (1988). The assessment of competition between seals and commercial fisheries in the North Sea and the Antarctic. Marine Mammal Science, 4, 13-33.

Heath, M. R. (2005). Changes in the structure and function of the North Sea fish foodweb, 19732000, and the impacts of fishing and climate. ICES Journal of Marine Science, 62, 847-868.

ICES. (2017). Report of the workshop on predator-prey interactions between grey seals and other marine mammals (WKPIGS), 30 April 2017. Middelfart, Denmark, ICES CM 2017/SSGEPD:18, 24 pp.

ICES. (2018a). Sandeel (Ammodytes spp.) in Divisions 4.b-c, Sandeel Area 1r (central and southern North Sea, Dogger Bank). ICES Advice.

ICES. (2018b). Sandeel (Ammodytes spp.) in Divisions 4.a-b, Sandeel Area 4 (northern and central North Sea). ICES Advice.

ICES. (2018c). Sandeel (Ammodytes spp.) in Divisions 4.a, Sandeel Area 7r (northern North Sea, Shetland). ICES Advice.

ICES. (2018d). Haddock (Melanogrammus aeglefinus) in Subarea 4, Division 6.a, and Subdivision 20 (North Sea, West of Scotland, Skagerrak). ICES Advice.

ICES. (2018e). Cod (Gadus morhua) in Subarea 4, Division 7.d, and Subdivision 20 (North Sea, eastern English Channel, Skagerrak). ICES Advice.

ICES. (2018f). Cod (Gadus morhua) in Division 6.a (West of Scotland). ICES Advice.

ICES. (2018g). Whiting (Merlangius merlangus) in Subarea 4 and Division 7.d (North Sea and eastern English Channel). ICES Advice. 
683 ICES. (2018h). Whiting (Merlangius merlangus) in Division 6.a (West of Scotland). ICES Advice.

684 Jones, E., McConnell, B., Sparling, C., \& Matthiopoulos, J. (2013). Marine mammal scientific support research programme MMSS/001/11, Grey and harbour seal density maps.

Krieber, M., \& Barrette, C. (1984). Aggregation Behaviour of Harbour Seals at Forillon National Park, Canada. Journal of Animal Ecology, 53, 913-928.

Leopold, M. F., van Damme, C. J. D., Philipart, C. J. M., \& Winter, C. J. N. (2001). Otoliths of North Sea fish - fish identification key by means of otoliths and other hard parts. . In CD ROM. Version 1.0. ETI (Expert Centre for Taxonomic Identification). University of Amsterdam, Amsterdam, The Netherlands.

Lonergan, M., Duck, C. D., Thompson, D., Mackey, B. L., Cunningham, L., \& Boyd, I. L. (2007). Using sparse survey data to investigate the declining abundance of British harbour seals. Journal of Zoology, 271, 261-269.

Lowry, L. F., Frost, K. J., Hoep, J. M., \& Delong, R. A. (2001). Movements of satellite-tagged subadult and adult harbor seals in Price William Sound, Alaska. Marine Mammal Science, 17, $835-861$.

Matejusová, I., Bland, F., Hall, A. J., Harris, R. N., Snow, M., Douglas, A., \& Middlemas, S. J. (2013). Real-time PCR assays for the identification of harbor and gray seal species and sex: A molecular tool for ecology and management. Marine Mammal Science, 29, 186-194.

Orr, A. J., Banks, A. S., Mellman, S., Huber, H. R., DeLong, R. L., \& Brown, R. F. (2004). Examination of the foraging habits of Pacific harbor seal (Phoca vitulina richardsi) to describe their use of the Umpqua River, Oregon, and their predation on salmonids. Fishery Bulletin, 102, 108-117.

Paine, R. T. (1984). Ecological determinism in the competition for space: the Robert H. MacArthur Award Lecture. Ecology, 65, 1339-1348.

Paine, R. T., Castillo, J. C., \& Cancino, J. (1985). Perturbation and recovery patterns of starfishdominated intertidal assemblages in Chile, New Zealand, and Washington State. The American Naturalist, 125, 679-691.

Paine, R. T., \& Trimble, A. C. (2004). Abrupt community change on a rocky shore-biological mechanisms contributing to the potential formation of an alternative state. Ecology Letters, 7 , 441-445.

Perry, A. L., Low, P. J., Ellis, J. R., \& Reynolds, J. D. (2005). Climate change and distribution shifts in marine fishes. Science, 308, 1912-1915.

Pierce, G. J., Boyle, P., \& Thompson, P. (1990). Diet selection by seals. In M. Barnes \& R. N. Gibson (Eds.), The European Marine Biology Symposium: Trophic Relationships in the Marine Environment (pp. 222-238): Aberdeen University Press.

Pierce, G. J., Miller, A., Thompson, P. M., \& Hislop, J. (1991). Prey remains in grey seal (Halichoerus grypus) faeces from the Moray Firth, north-east Scotland. Journal of Zoology, 224, 337-341.

Pierce, G. J., \& Santos, M. (2003). Diet of harbour seals (Phoca vitulina) in Mull and Skye (Inner Hebrides, western Scotland). Journal of the Marine Biological Association of the United Kingdom, 83, 647-650.

Prime, J., \& Hammond, P. (1990). The diet of grey seals from the south-western North Sea assessed from analyses of hard parts found in faeces. Journal of Applied Ecology, 27, 435-447.

Prime, J. H., \& Hammond, P. S. (1987). Quantitative assessment of grey seal diet from faecal analysis. In A. C. Huntley, D. P. Costa, G. A. J. Worthy, \& M. A. Castellini (Eds.), Approaches to marine mammal energetics. Lawrence, KS 66044, USA: Allen Press.

R Core Team. (2013). R: A language and environment for statistical computing. Vienna, Austria.: R Foundation for Statistical Computing.

Reder, S., Lydersen, C., Arnold, W., \& Kovacs, K. M. (2003). Haulout behaviour of High Arctic harbour seals (Phoca vitulina vitulina) in Svalbard, Norway. Polar Biology, 27, 6-16.

Russell, D. J., McClintock, B. T., Matthiopoulos, J., Thompson, P. M., Thompson, D., Hammond, P. S., . . McConnell, B. J. (2015). Intrinsic and extrinsic drivers of activity budgets in sympatric grey and harbour seals. Oikos, 124, 1462-1472. 
Santos, M., Clarke, M., \& Pierce, G. J. (2001). Assessing the importance of cephalopods in the diets of marine mammals and other top predators: problems and solutions. Fisheries Research, 52, 121-139.

SCOS. (2013). Scientific Advice on Matters Related to the Management of Seal Populations: 2013.

SCOS. (2017). Scientific Advice on Matters Related to the Management of Seal Populations: 2017.

Sea Mammal Research Unit. (2012). Workshop report on the decline in abundance of harbour seals around the coast of Scotland and discussion of mitigation and management measures, 28 August, 2012.

Sea Mammal Research Unit. (2014). Harbour Seal Decline Workshop II, 24th April, 2014. Report to Scottish Government.

Sharples, R. J., Arrizabalaga, B., \& Hammond, P. S. (2009). Seals, sandeels and salmon: diet of harbour seals in St. Andrews Bay and the Tay Estuary, southeast Scotland. Marine Ecology Progress Series, 390, 265-276.

Sharples, R. J., Moss, S. E., Patterson, T. A., \& Hammond, P. S. (2012). Spatial Variation in Foraging Behaviour of a Marine Top Predator (Phoca vitulina) Determined by a Large-Scale Satellite Tagging Program. PLoS ONE, 7.

Simberloff, D. (1978). Use of rarefaction and related methods in ecology. In K. L. Dickson, J. Cairns JR, \& R. J. Livingston (Eds.), Biological data in water pollution assessment: quantitative and statistical analyses (pp. 150-165). Philadelphia, PA, U.S.A: American Society for Testing and Materials.

Simpkins, M. A., Withrow, D. E., Cesarone, J. C., \& Boveng, P. L. (2003). Stability in the proportion of harbor seals hauled out under locally ideal conditions. Marine Mammal Science, 19, 791805.

Smith, B., \& Wilson, J. B. (1996). A consumer's guide to evenness indices. Oikos, 70-82.

Smout, S., Rindorf, A., Hammond, P., Harwood, J., \& Matthiopoulos, J. (2014). Modelling prey consumption by UK grey seals. ICES Journal of Marine Science, 71, 81-89.

Thompson, P. M., Mackay, A., Tollit, D. J., Enderby, S., \& Hammond, P. S. (1998). The influence of body size and sex on the characteristics of harbour seal foraging trips. Canadian Journal of Zoology, 76, 1044-1053.

Thompson, P. M., Miller, D., Cooper, R., \& Hammond, P. S. (1994). Changes in the Distribution and Activity of Female Harbour Seals During the Breeding Season: Implications for their Lactation Strategy and Mating Patterns. Journal of Animal Ecology, 63, 24-30.

Tollit, D., Steward, M., Thompson, P., Pierce, G. J., Santos, M., \& Hughes, S. (1997). Species and size differences in the digestion of otoliths and beaks: implications for estimates of pinniped diet composition. Canadian Journal of Fisheries and Aquatic Sciences, 54, 105-119.

Tollit, D., \& Thompson, P. (1996). Seasonal and between-year variations in the diet of harbour seals in the Moray Firth, Scotland. Canadian Journal of Zoology, 74, 1110-1121.

Trijoulet, V., Holmes, S. J., \& Cook, R. M. (2017). Grey seal predation mortality on three depleted stocks in the West of Scotland: What are the implications for stock assessments? Canadian Journal of Fisheries and Aquatic Sciences, 75, 723-732.

van Neer, A., Jensen, L. F., \& Siebert, U. (2015). Grey seal (Halichoerus grypus) predation on harbour seals (Phoca vitulina) on the island of Helgoland, Germany. Journal of Sea Research, 97, 1-4.

Wanless, S., Harris, M., Redman, P., \& Speakman, J. (2005). Low energy values of fish as a probable cause of a major seabird breeding failure in the North Sea. Marine Ecology Progress Series, 294, 1-8.

Wilson, L., \& Hammond, P. (2016). Harbour seal diet composition and diversity. Marine Mammal Scientific Support Research Programme MMSS/001/11 CSD 3.2. Report to the Scottish Government.

Wilson, L. J. (2014). The diet and feeding ecology of harbour seals around Britain. University of St Andrews.

Wilson, L. J., Grellier, K., \& Hammond, P. S. (2017). Improved estimates of digestion correction factors and passage rates for harbor seal (Phoca vitulina) prey in the northeast Atlantic. Marine Mammal Science, 33, 1149-1169. 
790 viii. Tables

791 Table 1: Number of harbour and grey seal scat samples containing hard prey remains (fish 792 otoliths and cephalopod beaks), the total number of hard prey remains recovered and the 793 number of otoliths/beaks measured for each region and season (SS = spring/summer; AW = 794 autumn/winter).

\begin{tabular}{|c|c|c|c|c|c|c|c|}
\hline \multirow[t]{2}{*}{ Region } & \multirow[t]{2}{*}{ Season } & \multicolumn{2}{|c|}{$\begin{array}{l}\text { Scats containing } \\
\text { otoliths/beaks }\end{array}$} & \multicolumn{2}{|c|}{$\begin{array}{l}\text { Otoliths/ beaks } \\
\text { recovered }\end{array}$} & \multicolumn{2}{|c|}{$\begin{array}{l}\text { Otoliths / beaks } \\
\text { measured }\end{array}$} \\
\hline & & Harbour & Grey & Harbour & Grey & Harbour & Grey \\
\hline Southern & SS & 145 & 86 & 4,148 & 4,401 & 2,790 & 1,899 \\
\hline North Sea & AW & 143 & 75 & 2,790 & 3,277 & 1,919 & 1,548 \\
\hline \multirow{2}{*}{ SE Scotland } & SS & 22 & 107 & 2,018 & 4,667 & 716 & 1,998 \\
\hline & AW & 17 & 162 & 4,208 & 5,105 & 1,419 & 2,516 \\
\hline \multirow{2}{*}{ Moray Firth } & SS & 192 & 29 & 17,037 & 2,740 & 6,452 & 865 \\
\hline & AW & 73 & 90 & 3,484 & 7,991 & 1,506 & 2,905 \\
\hline \multirow{2}{*}{ Orkney } & SS & 140 & 57 & 4,932 & 1,332 & 2,813 & 767 \\
\hline & AW & 117 & 563 & 1,529 & 12,292 & 986 & 7,872 \\
\hline \multirow{2}{*}{ Shetland } & SS & 75 & 45 & 2,145 & 492 & 1,233 & 465 \\
\hline & AW & 111 & 206 & 2,622 & 3,647 & 1,642 & 2,472 \\
\hline Outer & SS & 99 & & 1,584 & & 1,180 & \\
\hline Hebrides & AW & 13 & 274 & 799 & 5,300 & 385 & 3,419 \\
\hline Inner & SS & 438 & 18 & 10,627 & 104 & 8,804 & 103 \\
\hline Hebrides & AW & 391 & 314 & 7,611 & 4,904 & 5,384 & 4,056 \\
\hline
\end{tabular}

795

796 
797 Table 2: Seasonal variation in the diet of harbour and grey seals, expressed as the 798 percentage of each prey group in the diet by weight.

A) Southern North Sea

\begin{tabular}{lllll}
\hline & \multicolumn{2}{l}{ Spring / Summer } & \multicolumn{2}{l}{ Autumn / Winter } \\
Prey type & harbour & grey & harbour & grey \\
\hline Gadid & 3.8 & 11.5 & 29.6 & 11.0 \\
Trisopterus & 1.1 & 0.9 & 0.5 & 0.2 \\
Sandeel & 20.8 & 70.6 & 6.5 & 47.0 \\
Flatfish & 29.0 & 10.7 & 31.3 & 10.0 \\
Sandy benthic & 43.5 & 4.4 & 18.7 & 11.2 \\
Scorpion fish & 1.0 & 1.5 & 6.9 & 19.6 \\
Pelagic & 0.3 & 0.0 & 3.5 & 1.0 \\
Salmonid & 0.0 & 0.0 & 0.0 & 0.0 \\
Cephalopod & 0.0 & 0.5 & 2.9 & 0.0 \\
Other & 0.4 & 0.1 & 0.2 & 0.0 \\
\hline
\end{tabular}

B) Southeast Scotland

\begin{tabular}{lllll}
\hline & \multicolumn{2}{l}{ Spring / Summer } & \multicolumn{2}{l}{ Autumn / Winter } \\
Prey type & harbour & grey & harbour & grey \\
\hline Gadid & 10.3 & 1.7 & 16.9 & 13.7 \\
Trisopterus & 0.0 & 0.1 & 0.0 & 0.4 \\
Sandeel & 44.5 & 89.1 & 0.0 & 60.7 \\
Flatfish & 38.7 & 6.3 & 49.7 & 12.5 \\
Sandy benthic & 0.0 & 1.0 & 5.9 & 1.1 \\
Scorpion fish & 0.0 & 0.6 & 1.3 & 8.3 \\
Pelagic & 1.0 & 1.0 & 13.4 & 2.1 \\
Salmonid & 1.4 & 0.0 & 0.2 & 0.0 \\
Cephalopod & 4.2 & 0.2 & 11.4 & 0.5 \\
Other & 0.0 & 0.0 & 1.3 & 0.7 \\
\hline
\end{tabular}

C) Moray Firth

\begin{tabular}{lllll}
\hline & \multicolumn{2}{l}{ Spring / Summer } & \multicolumn{2}{l}{ Autumn / Winter } \\
Prey type & harbour & grey & harbour & grey \\
\hline Gadid & 2.2 & 0.2 & 5.9 & 11.6 \\
Trisopterus & 0.0 & 0.0 & 0.2 & 0.5 \\
Sandeel & 67.1 & 97.6 & 72.7 & 75.6 \\
Flatfish & 24.5 & 1.1 & 7.6 & 4.1 \\
Sandy benthic & 0.1 & 0.1 & 1.0 & 1.8
\end{tabular}




\begin{tabular}{lllll} 
Scorpion fish & 2.3 & 0.0 & 3.4 & 6.0 \\
Pelagic & 1.6 & 0.7 & 5.1 & 0.1 \\
Salmonid & 0.5 & 0.0 & 3.0 & 0.0 \\
Cephalopod & 1.7 & 0.0 & 0.5 & 0.1 \\
Other & 0.1 & 0.2 & 0.5 & 0.1 \\
\hline
\end{tabular}

D) Orkney

\begin{tabular}{lllll}
\hline & \multicolumn{2}{l}{ Spring / Summer } & \multicolumn{2}{l}{ Autumn / Winter } \\
Prey type & harbour & grey & harbour & grey \\
\hline Gadid & 30.8 & 42.3 & 39.2 & 34.0 \\
Trisopterus & 1.1 & 11.4 & 0.2 & 3.6 \\
Sandeel & 53.2 & 21.9 & 17.6 & 34.3 \\
Flatfish & 6.0 & 3.6 & 6.1 & 8.3 \\
Sandy benthic & 1.1 & 2.5 & 3.4 & 2.0 \\
Scorpion fish & 2.8 & 8.8 & 0.2 & 10.1 \\
Pelagic & 4.4 & 5.3 & 30.9 & 4.1 \\
Salmonid & 0.0 & 0.0 & 0.0 & 0.0 \\
Cephalopod & 0.4 & 2.3 & 1.8 & 3.4 \\
Other & 0.3 & 1.9 & 0.6 & 0.3 \\
\hline
\end{tabular}

E) Shetland

\begin{tabular}{lllll}
\hline & \multicolumn{2}{l}{ Spring / Summer } & \multicolumn{2}{l}{ Autumn / Winter } \\
Prey type & harbour & grey & harbour & grey \\
\hline Gadid & 23.9 & 35.3 & 27.6 & 31.9 \\
Trisopterus & 8.6 & 4.5 & 5.9 & 3.0 \\
Sandeel & 23.7 & 18.8 & 31.5 & 33.3 \\
Flatfish & 1.3 & 6.5 & 3.9 & 5.4 \\
Sandy benthic & 10.1 & 0.3 & 0.9 & 11.5 \\
Scorpion fish & 0.0 & 33.6 & 0.0 & 6.0 \\
Pelagic & 31.4 & 0.0 & 20.0 & 1.9 \\
Salmonid & 0.0 & 0.0 & 0.0 & 1.4 \\
Cephalopod & 0.9 & 0.9 & 0.2 & 1.9 \\
Other & 0.0 & 0.0 & 10.0 & 3.6 \\
\hline
\end{tabular}

F) Outer Hebrides

\begin{tabular}{lllll} 
& \multicolumn{2}{l}{ Spring / Summer } & \multicolumn{2}{c}{ Autumn / Winter } \\
Prey type & harbour & grey & harbour & grey \\
\hline Gadid & 17.2 & & & 32.4
\end{tabular}




\begin{tabular}{ll|l} 
Trisopterus & 24.5 & 6.8 \\
Sandeel & 13.1 & 38.2 \\
Flatfish & 2.0 & 6.6 \\
Sandy benthic & 2.8 & 3.5 \\
Scorpion fish & 16.2 & 0.5 \\
Pelagic & 20.3 & 3.9 \\
Salmonid & 0.0 & 0.0 \\
Cephalopod & 3.8 & 3.3 \\
Other & 0.3 & 4.8 \\
\hline
\end{tabular}

799

G) Inner Hebrides

\begin{tabular}{lllll}
\hline & \multicolumn{2}{l}{ Spring / Summer } & \multicolumn{2}{l}{ Autumn / Winter } \\
Prey type & harbour & grey & harbour & grey \\
\hline Gadid & 54.5 & 38.2 & 35.0 & 32.4 \\
Trisopterus & 14.0 & 14.6 & 8.2 & 7.6 \\
Sandeel & 3.2 & 8.0 & 4.2 & 22.2 \\
Flatfish & 2.7 & 3.1 & 5.0 & 8.3 \\
Sandy benthic & 3.8 & 32.0 & 15.7 & 11.2 \\
Scorpion fish & 3.0 & 0.0 & 1.6 & 4.9 \\
Pelagic & 16.5 & 2.8 & 28.8 & 1.0 \\
Salmonid & 0.1 & 0.0 & 0.0 & 0.0 \\
Cephalopod & 2.2 & 1.2 & 1.0 & 4.0 \\
Other & 0.1 & 0.0 & 0.4 & 8.3
\end{tabular}

800 
802 Table 3: Number of scats containing hard prey remains, observed and rarefied species 803 richness, and species evenness. Data were rarefied within region/season combinations, so 804 comparisons of species richness or evenness should only be made between seal species 805 within seasons, not across regions, or across seasons within a region.

806

A) Southern North Sea

\begin{tabular}{lllll}
\hline & No. scats & $\begin{array}{l}\text { Observed No. } \\
\text { prey species }\end{array}$ & Species richness (S) & Species Evenness (PIE) \\
\cline { 2 - 5 } Spring/Summer & & & 21 & 0.77 \\
Harbour seal & 145 & 26 & 24 & 0.14 \\
Grey seal & 86 & 28 & & 0.81 \\
Autumn/Winter & & & 23 & 0.3 \\
Harbour seal & 143 & 29 & 22 & \\
Grey seal & 75 & 24 & & \\
\hline
\end{tabular}

B) South east Scotland

\begin{tabular}{lllll}
\hline & No. scats & $\begin{array}{l}\text { Observed No. } \\
\text { prey species }\end{array}$ & Species richness (S) & Species Evenness (PIE) \\
\cline { 2 - 5 } Spring/Summer & & & 10 & 0.38 \\
Harbour seal & 22 & 12 & 8 & 0.04 \\
Grey seal & 107 & 18 & 19 & 0.51 \\
Autumn/Winter & & & 14 & 0.24 \\
Harbour seal & 17 & 22 & 31 &
\end{tabular}

C) Moray Firth

\begin{tabular}{lllll}
\hline & No. scats & $\begin{array}{l}\text { Observed No. } \\
\text { prey species }\end{array}$ & Species richness (S) & Species Evenness (PIE) \\
\cline { 2 - 5 } Spring/Summer & & & 14 & 0.1 \\
Harbour seal & 192 & 28 & 9 & 0.01 \\
Grey seal & 29 & 10 & & \\
Autumn/Winter & & & 18 & 0.12 \\
Harbour seal & 73 & 21 & 27 & 0.07 \\
Grey seal & 90 & 32 & & \\
\hline
\end{tabular}

D) Orkney

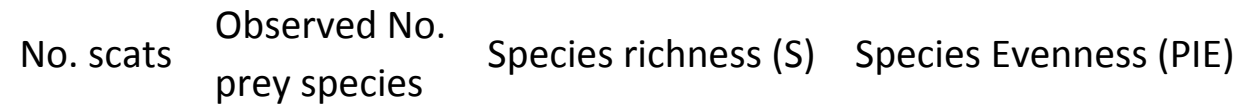




\begin{tabular}{lllll} 
Harbour seal & 140 & 34 & 24 & 0.3 \\
Grey seal & 57 & 35 & 31 & 0.71 \\
\hline Autumn/Winter & & & & \\
Harbour seal & 117 & 25 & 23 & 0.41 \\
Grey seal & 563 & 61 & 42 & 0.57 \\
\hline
\end{tabular}

E) Shetland

\begin{tabular}{lllll}
\hline & No. scats & $\begin{array}{l}\text { Observed No. } \\
\text { prey species }\end{array}$ & Species richness (S) & Species Evenness (PIE) \\
\cline { 2 - 5 } Spring/Summer & & & 17 & 0.54 \\
Harbour seal & 75 & 25 & 20 & 0.77 \\
Grey seal & 45 & 24 & & \\
Autumn/Winter & & & 21 & 0.45 \\
Harbour seal & 111 & 24 & 40 & 0.56 \\
Grey seal & 206 & 47 & & \\
\hline
\end{tabular}

F) Outer Hebrides

\begin{tabular}{lllll}
\hline & No. scats & $\begin{array}{l}\text { Observed No. } \\
\text { prey species }\end{array}$ & Species richness (S) & Species Evenness (PIE) \\
\hline $\begin{array}{lllll}\text { Spring/Summer } \\
\text { Harbour seal }\end{array}$ & 99 & 22 & 20 & 0.73 \\
$\begin{array}{l}\text { Autumn/Winter } \\
\text { Grey seal }\end{array}$ & 274 & 46 & 41 & 0.46 \\
\hline
\end{tabular}

G) Inner Hebrides

\begin{tabular}{lllll}
\hline & No. scats & $\begin{array}{l}\text { Observed No. } \\
\text { prey species }\end{array}$ & Species richness (S) & Species Evenness (PIE) \\
\cline { 2 - 5 } Spring/Summer & & & 19 & 0.82 \\
Harbour seal & 438 & 49 & 11 & 0.82 \\
Grey seal & 18 & 13 & & \\
Autumn/Winter & & & 46 & 0.87 \\
Harbour seal & 391 & 52 & 49 & 0.77 \\
Grey seal & 314 & 53 & &
\end{tabular}


808 Table 4: Summary comparison table of harbour seal (Pv) and grey seal ( $\mathrm{Hg}$ ) diets. Trend is the population trajectory of seals in each region since 2000 (SCOS,

809 2013): $\pi=$ population increasing, $--=$ population stable and $\boldsymbol{\nabla}=$ population declining. SS $=$ spring/summer; $A W=$ autumn/winter. Species evenness: $\mathrm{H}=$

810 high (PIE > 0.75), $M=$ moderate ( $P I E=0.3-0.75)$ and $\mathrm{L}=$ low $(\mathrm{PIE}<0.3)$. Diet composition: prey groups are listed in order of dominance and include those

811 that together comprise at least two-thirds of the diet, by weight. Strongly dominant prey groups (in bold) are defined as top ranked prey groups

812 contributing $>45 \%$ to the diet and a greater \% than the sum of prey groups ranked 2, 3 and 4 .

813

\begin{tabular}{|c|c|c|c|c|c|c|c|c|}
\hline \multirow[b]{3}{*}{ Region } & \multirow{2}{*}{\multicolumn{2}{|c|}{ Trend }} & \multicolumn{2}{|c|}{ Species evenness } & \multicolumn{4}{|c|}{ Diet composition } \\
\hline & & & SS & AW & \multicolumn{2}{|c|}{ SS } & \multicolumn{2}{|c|}{ AW } \\
\hline & $\mathrm{Pv}$ & $\mathrm{Hg}$ & $\mathrm{Pv} \quad \mathrm{Hg}$ & $\mathrm{Pv} \mathrm{Hg}$ & $\mathrm{Pv}$ & $\mathrm{Hg}$ & $\mathrm{Pv}$ & $\mathrm{Hg}$ \\
\hline $\begin{array}{l}\text { Southern } \\
\text { North Sea }\end{array}$ & $\pi$ & $\pi$ & $H>L$ & $H>L$ & $\begin{array}{l}\text { sandy benthic } \\
\text { flatfish }\end{array}$ & sandeel & $\begin{array}{c}\text { flatfish } \\
\text { gadid } \\
\text { sandy benthic }\end{array}$ & $\begin{array}{c}\text { sandeel } \\
\text { scorpion fish }\end{array}$ \\
\hline SE Scotland & $y$ & $\pi$ & $M>L$ & $M>L$ & $\begin{array}{l}\text { sandeel } \\
\text { flatfish }\end{array}$ & sandeel & $\begin{array}{c}\text { flatfish } \\
\text { gadid }\end{array}$ & $\begin{array}{l}\text { sandeel } \\
\text { gadid }\end{array}$ \\
\hline Moray Firth & -- & $\pi$ & $\mathrm{L}=\mathrm{L}$ & $\mathrm{L}=\mathrm{L}$ & sandeel & sandeel & sandeel & sandeel \\
\hline Orkney & $y$ & -- & $L<M$ & $M=M$ & $\begin{array}{l}\text { sandeel } \\
\text { gadid }\end{array}$ & $\begin{array}{c}\text { gadid } \\
\text { sandeel } \\
\text { Trisopterus }\end{array}$ & $\begin{array}{l}\text { gadid } \\
\text { pelagic }\end{array}$ & $\begin{array}{l}\text { sandeel } \\
\text { gadid }\end{array}$ \\
\hline Shetland & $y$ & -- & $\mathrm{M}<\mathrm{H}$ & $M=M$ & $\begin{array}{c}\text { pelagic } \\
\text { gadid } \\
\text { sandeel }\end{array}$ & $\begin{array}{l}\text { gadid } \\
\text { scorpion fish }\end{array}$ & $\begin{array}{c}\text { sandeel } \\
\text { gadid } \\
\text { pelagic }\end{array}$ & $\begin{array}{c}\text { sandeel } \\
\text { gadid } \\
\text { sandy benthic }\end{array}$ \\
\hline $\begin{array}{l}\text { Outer } \\
\text { Hebrides }\end{array}$ & $\pi$ & -- & $\mathrm{M}$ & $\mathrm{M}$ & $\begin{array}{l}\text { Trisopterus } \\
\text { pelagic } \\
\text { gadid } \\
\text { scorpion fish }\end{array}$ & & & $\begin{array}{l}\text { sandeel } \\
\text { gadid }\end{array}$ \\
\hline $\begin{array}{l}\text { Inner } \\
\text { Hebrides }\end{array}$ & -- & -- & $\mathrm{H}=\mathrm{H}$ & $\mathrm{H}=\mathrm{H}$ & $\begin{array}{l}\text { gadid } \\
\text { pelagic }\end{array}$ & $\begin{array}{c}\text { gadid } \\
\text { sandy benthic }\end{array}$ & $\begin{array}{c}\text { gadid } \\
\text { pelagic } \\
\text { sandy benthic }\end{array}$ & $\begin{array}{c}\text { gadid } \\
\text { sandeel } \\
\text { sandy benthic }\end{array}$ \\
\hline
\end{tabular}

814 